\title{
Lung function trajectories in children with post-prematurity respiratory disease: identifying risk factors for abnormal growth
}

Jonathan C. Levin ${ }^{1,2^{*}}\left(\mathbb{D}\right.$, Catherine A. Sheils ${ }^{2}$, Jonathan M. Gaffin ${ }^{2}$, Craig P. Hersh ${ }^{3}$, Lawrence M. Rhein ${ }^{4}$ and Lystra P. Hayden ${ }^{2,3}$

\begin{abstract}
Background: Survivors of prematurity are at risk for abnormal childhood lung function. Few studies have addressed trajectories of lung function and risk factors for abnormal growth in childhood. This study aims to describe changes in lung function in a contemporary cohort of children born preterm followed longitudinally in pulmonary clinic for post-prematurity respiratory disease and to assess maternal and neonatal risk factors associated with decreased lung function trajectories.
\end{abstract}

Methods: Observational cohort of 164 children born preterm $\leq 32$ weeks gestation followed in pulmonary clinic at Boston Children's Hospital with pulmonary function testing. We collected demographics and neonatal history. We used multivariable linear regression to identify the impact of neonatal and maternal risk factors on lung function trajectories in childhood.

Results: We identified 264 studies from 82 subjects with acceptable longitudinal FEV 1 data and 138 studies from 47 subjects with acceptable longitudinal $\mathrm{FVC}$ and $\mathrm{FEV}_{1} / \mathrm{FVC}$ data. $\mathrm{FEV}_{1} \%$ predicted and $\mathrm{FEV}_{1} / \mathrm{FVC}$ were reduced compared to childhood norms. Growth in FVC outpaced FEV 1 , resulting in an $\mathrm{FEV}_{1} / \mathrm{FVC}$ that declined over time. In multivariable analyses, longer duration of mechanical ventilation was associated with a lower rate of rise in $\mathrm{FEV}, \%$ predicted and greater decline in $\mathrm{FEV}_{1} / \mathrm{FVC}$, and postnatal steroid exposure in the NICU was associated with a lower rate of rise in $\mathrm{FEV}_{1}$ and $\mathrm{FVC} \%$ predicted. Maternal atopy and asthma were associated with a lower rate of rise in $\mathrm{FEV}_{1} \%$ predicted.

Conclusions: Children with post-prematurity respiratory disease demonstrate worsening obstruction in lung function throughout childhood. Neonatal risk factors including exposure to mechanical ventilation and postnatal steroids, as well as maternal atopy and asthma, were associated with diminished rate of rise in lung function. These results may have implications for lung function trajectories into adulthood.

Keywords: Pulmonary function tests, Bronchopulmonary dysplasia, Chronic lung disease of prematurity

\section{Introduction}

Survivors of prematurity are at risk for respiratory morbidity and abnormal lung function throughout life [1].

*Correspondence: Jonathan.Levin@childrens.harvard.edu

${ }^{1}$ Division of Newborn Medicine, Boston Children's Hospital, 300 Longwood Ave Hunnewell 4, Boston, MA 02115, USA

Full list of author information is available at the end of the article
Post-prematurity respiratory disease, including bronchopulmonary dysplasia (BPD), may be a progenitor to adult chronic obstructive pulmonary disease [2-5]. BPD affects up to $40 \%$ of former preterm infants born at $<28$ weeks gestation, with about 10,000 new cases of BPD in the United States every year [6, 7]. Of survivors with $\mathrm{BPD}$, more than $50 \%$ may have abnormal lung 
function when they are of school age [8]. Pulmonary function in survivors with BPD often demonstrates an obstructive pattern, specifically with regard to decreased forced expiratory volumes in one second $\left(\mathrm{FEV}_{1}\right)$ and decreased ratio of $\mathrm{FEV}_{1}$ to Forced Vital Capacity (FVC) [8-10]. Adulthood survivors of prematurity demonstrate ongoing obstructive abnormalities that persist beyond childhood [11-13].

Infants born preterm since the early 1990s, when surfactant, antenatal steroids, and lung-protective ventilation became standards of care, are just reaching young adulthood [14]. Longitudinal follow-up among survivors of prematurity with ongoing lung disease is becoming increasingly important to understand the long-term outcomes and healthcare needs in this population $[15,16]$. Classically, recovery of lung function from prematurity is believed to be possible with ongoing alveolar growth through childhood, in the absence of ongoing pulmonary insults [17]. However, few studies have addressed trajectories of lung function and risk factors for abnormal growth.

Survivors of prematurity may have an abnormal growth in pulmonary function as evidence by diminished rate of rise during childhood and adolescence, abnormal peak lifetime function, and a more rapid decline in lung function in adulthood [18]. Available data of serial measurements of pulmonary function in this population suggest worsening airway obstruction over time in children with a diagnosis of BPD [19-24]. However, to our knowledge pulmonary function trajectories have not been reported in a United States based cohort. Furthermore, few contemporary studies focus on identifying risk factors from the neonatal and early childhood course associated with abnormal pulmonary function trajectories in childhood.

We aimed to characterize lung function trajectories in a contemporary observational cohort of children with post-prematurity respiratory disease followed in pulmonary clinic at Boston Children's Hospital. Our objectives were to (1) describe childhood spirometry in a cohort of children born preterm with chronic respiratory disease, (2) measure changes in spirometry values over time in children with serial lung function measurements, and (3) identify risk factors from the neonatal course associated with decreased lung function trajectories. We hypothesized that survivors of prematurity with respiratory disease would demonstrate an obstructive pattern of pulmonary function, and that those with more severe disease in the neonatal period would demonstrate less potential for improvement in lung function during childhood.

\section{Methods}

\section{Subjects}

We selected subjects who performed spirometry from a patient registry of former preterm infants born $\leq 32$ weeks gestational age (GA) followed at the Boston Children's Hospital Preterm Lung Patient Registry between 2008 and 2019 (March 29, 2019 lung function dataset). The patient registry includes former preterm infants followed by pulmonology for post-prematurity respiratory disease and is approved by the institutional review board at Boston Children's Hospital. Informed consent was obtained for each participant enrolled after 2008; an additional 38 subjects were enrolled under a waiver of consent for retrospective review. Excluded are those with known cyanotic cardiac lesions, genetic syndromes, or congenital malformations that contribute to their respiratory disease. Subjects were seen as clinically indicated, typically at least every 3 months in the first year of life, every 6 months in the second year, and annually thereafter; more frequent visits are as indicated based on symptoms and clinical course.

\section{Measurements}

Demographics, neonatal intensive care unit (NICU) history, and maternal information were collected after enrollment including questionnaire data collected at clinic visits. Details of the NICU course were obtained from NICU discharge summaries. BPD was defined based upon modified National Heart Lung and Blood Institute (NHLBI) criteria as having used at least 28 days of oxygen after birth with severity assessed based on respiratory support at 36 weeks post-menstrual age [25]. Respiratory support at 36 weeks and at discharge was defined as nasal cannula oxygen, positive pressure, or mechanical ventilation. Subjects without an available BPD severity were included in the overall lung function analyses but removed from analyses subset on BPD severity. Tobacco exposure, both during pregnancy and secondhand exposure in the home, was based on questionnaires collected as part of the patient registry during clinic visits. Maternal asthma, hay fever, and eczema were self-reported; atopy was defined as having at least one of these diagnoses. When available, follow-up questionnaires completed in the first three years of life were used, which included data on respiratory illnesses (defined as bronchiolitis, reactive airway disease, asthma flare, BPD flare, or pneumonia), medication use, and palivizumab and influenza vaccination. These questionnaires were administered up to every 6 months in frequency, and responses over the first three years were aggregated such that as 'yes' response on any individual questionnaire was recorded as a 'yes' overall. 
Subjects performed pre-bronchodilator spirometry as clinically indicated according to American Thoracic Society Guidelines on a Medisoft SpiroAir ${ }^{\circledR}$ machine (Sorinnes, Belgium); data were recorded in and extracted from Morgan Scientific ComPAS software (Haverhill, MA, USA) [26]. Spirometry was normalized using Global Lung Function Initiative (GLI) equations to obtain percent predicted values [27]. Each test was visually assessed using modified pediatric American Thoracic Society criteria, including acceptability of $\mathrm{FEV}_{1}$ and FVC (see Additional file 1). Studies were excluded completely if they did not meet criteria for $\mathrm{FEV}_{1}$ on at least one effort; FVC data was only included from studies that had acceptable end-effort criteria. We selected year's best pre-bronchodilator spirometry efforts for $\mathrm{FEV}_{1} \%$ predicted, $\mathrm{FVC} \%$ predicted, and $\mathrm{FEV}_{1} / \mathrm{FVC}$ ratio for each year the subject completed spirometry to avoid bias of testing obtained during time of illness. Post bronchodilator data were obtained based on clinical indication, and a greater than $10 \%$ change was considered a positive response. Pulmonary function trajectories were assessed in subjects with at least two pre-bronchodilator spirometry efforts at different ages.

\section{Statistical analysis}

Primary analysis was performed using a two staged model for lung function trajectories [28]. This two-staged model was preferred over a linear mixed effects model as to give each subject equal weighting; subjects with more measurements could otherwise bias the model towards those with more severe disease, who may have had more frequent lung function measurements. In the first stage, linear models were used to calculate the change for each subject in $\mathrm{FEV}_{1} \%$ predicted / year, $\mathrm{FVC} \%$ predicted / year, and $\mathrm{FEV}_{1} / \mathrm{FVC}$ (absolute) / year. In the second stage, the coefficient from each subjects' individual model was used as the outcome variable in a multivariable linear regression to examine effects of neonatal exposures and change in pulmonary function over time. This regression was controlled for GA, birthweight (BW), and first spirometry value. As height, age, race and gender are incorporated in percent predicted values, we did not adjust for these characteristics separately in multivariable analyses. We used a significance level of $\mathrm{p}<0.05$. Results were reported as absolute differences $(\beta)$ with $95 \%$ confidence intervals. Subjects with missing data were removed from specific analyses. Analysis was performed using $\mathrm{R}$ v4.0.2 (2020-06-22) with packages tidyverse v1.3, lme4 v1.1.23, ggplot2 v3.3.2, and rspiro v0.2.

\section{Sensitivity analyses}

A sensitivity analysis was performed using linear mixed effect models with pulmonary function as the outcome, using subject and age as random effects, and using neonatal exposures, GA, BW, age, and the interaction term of (neonatal exposure *age) as fixed effects [24].

Given that most available spirometry in this cohort was performed at $\leq 12$ years of age, a separate sensitivity analysis only using these data was performed, removing those studies performed after this point from analysis.

\section{Results}

We identified 164 former preterm infants $\leq 32$ weeks GA with pulmonary function testing (Fig. 1). These subjects were predominantly Caucasian, with a slight male predominance (54\%). Median GA was $261 / 7$ weeks with median BW $877 \mathrm{~g}$. The plurality of subjects had moderate to severe BPD, with a high degree of respiratory and other neonatal morbidities, including need for surfactant, postnatal steroid exposure in the NICU, patent ductus arteriosus (PDA) ligation, gastrostomy tube placement, and respiratory support at 36 weeks post-menstrual age (Table 1). Self-reported tobacco exposure was low. There were high rates of self-reported maternal atopy. Followup data over the first three years of age were available for 42 infants; nearly half required an emergency department visit or hospitalization for respiratory illness, and one-third developed a lower respiratory tract infection. Though subjects were born over a wide timespan (1999_ 2014), using linear or logistical regression with birth year as a covariate there was no evidence for change over time for GA, BW, surfactant, antenatal steroids, ventilated or CPAP days, PDA diagnosis, PDA ligation, necrotizing enterocolitis, gastrostomy, and moderate/severe BPD. Over time, tracheostomy placement decreased $(\mathrm{p}=0.03)$ as did postnatal steroid use $(\mathrm{p}=0.004)$.

\section{Pulmonary function studies}

Subjects performed 541 distinct spirometry sessions, with an average age of six years at testing and an average of three sessions per subject. There were 483 tests $(89 \%)$ from 155 subjects (94\%) with acceptable $\mathrm{FEV}_{1}$ data and

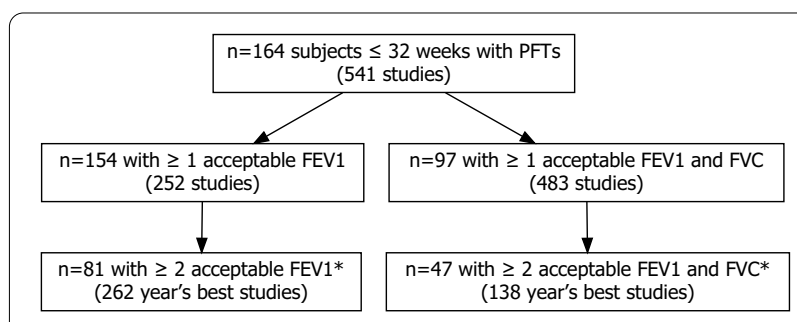

Fig. 1 Study flow diagram. *Studies performed at different ages 
Table 1 Subject characteristics

\begin{tabular}{|c|c|}
\hline & $N=164$ \\
\hline \multicolumn{2}{|l|}{ Demographics } \\
\hline Median birth year, (range) & 2008 (1999-2014) \\
\hline Males, no. (\%) & $88(54 \%)$ \\
\hline \multicolumn{2}{|l|}{ Race, no. (\%) } \\
\hline White & $129(79 \%)$ \\
\hline Black & $14(9 \%)$ \\
\hline Asian & $2(1 \%)$ \\
\hline Other & $19(11 \%)$ \\
\hline Hispanic, no./total (\%) & 19/151 (13\%) \\
\hline \multicolumn{2}{|l|}{ Maternal history } \\
\hline Median maternal age (IQR) & $33(29.25-37)$ \\
\hline Maternal asthma, no./total (\%) & $38 / 105(36 \%)$ \\
\hline Maternal hay fever, no./total (\%) & $31 / 105(30 \%)$ \\
\hline Maternal eczema, no./total (\%) & 26/106 (25\%) \\
\hline Maternal atopy, no./total (\%) & $60 / 106(57 \%)$ \\
\hline \multicolumn{2}{|l|}{ Neonatal history } \\
\hline Median gestational age, weeks (range) & $261 / 7(233 / 7-32)$ \\
\hline Median birth weight, grams (range) & $813(455-1927)$ \\
\hline Small for gestational age, no. (\%) & $13(8 \%)$ \\
\hline Multiple gestation, no. (\%) & $67 / 163(41 \%)$ \\
\hline \multicolumn{2}{|l|}{ Bronchopulmonary dysplasia, no. (\%) } \\
\hline None & $16(9 \%)$ \\
\hline Mild & $15(10 \%)$ \\
\hline Moderate & $49(30 \%)$ \\
\hline Severe & $68(41 \%)$ \\
\hline Unclassified & $16(10 \%)$ \\
\hline Antenatal corticosteroid (any), no. (\%) & $114 / 136(84 \%)$ \\
\hline Antenatal steroid (complete), no. (\%) & $83 / 105(78 \%)$ \\
\hline Median ventilated days (IQR) & $31(8-49)$ \\
\hline Median CPAP days (IQR) & $25(10-40)$ \\
\hline Surfactant, no./total (\%) & 138/142 (97\%) \\
\hline PDA, no./total (\%) & $117 / 150(78 \%)$ \\
\hline PDA ligation, no./total (\%) & $50 / 148(34 \%)$ \\
\hline NEC, no./total (\%) & 25/148 (17\%) \\
\hline \multicolumn{2}{|l|}{ Intraventricular hemorrhage, no./total (\%) } \\
\hline Grade I/II & $25 / 97(27 \%)$ \\
\hline Grade III/IV/periventricular leukomalacia & $7 / 97(7 \%)$ \\
\hline Gastrostomy tube, no./total (\%) & $42 / 142(30 \%)$ \\
\hline Tracheostomy, no./total (\%) & $14 / 145(10 \%)$ \\
\hline Postnatal steroids (NICU), no./total (\%) & $41 / 106(33 \%)$ \\
\hline \multicolumn{2}{|l|}{ Breastmilk nutrition at discharge no./total (\%) } \\
\hline Exclusive breastmilk & $39 / 150(26 \%)$ \\
\hline Mixed & $54 / 150(36 \%)$ \\
\hline Formula & $57 / 150(38 \%)$ \\
\hline Resp support or $\mathrm{O}_{2}$ at 36 wk, no./total (\%) & $117 / 149(79 \%)$ \\
\hline Resp support or $\mathrm{O}_{2}$ at discharge, no./total (\%) & $80 / 160(50 \%)$ \\
\hline \multicolumn{2}{|l|}{ Tobacco exposure } \\
\hline Maternal tobacco use, no./total (\%) & $3 / 107(3 \%)$ \\
\hline Secondhand smoke exposure in home, no./total (\%) & $11 / 164(7 \%)$ \\
\hline
\end{tabular}

Table 1 (continued)

\begin{tabular}{ll}
\hline & $\mathbf{N}=\mathbf{1 6 4}$ \\
\hline Follow-up 0-3 years ( $n=42$ with data) & \\
\hline Received palivizumab & $25 / 32(60 \%)$ \\
Received flu shot & $36 / 42(86 \%)$ \\
ER or hospitalization for respiratory cause & $19(45 \%)$ \\
Hospitalization for respiratory cause & $7(17 \%)$ \\
Lower respiratory tract infection & $14(33 \%)$ \\
Spirometry & \\
Mean age at spirometry, years (range) & $6.7(3-20)$ \\
Mean number of studies per subject, (range) & $3.3(1-18)$ \\
\hline
\end{tabular}

IQR Interquartile range, $B W$ birthweight, $G A$ gestational age, $P D A$ patent ductus arteriosus, NEC necrotizing enterocolitis. When a distinct total is listed, there was missing data not included in analysis. Lower respiratory tract infection defined as bronchiolitis, asthma flare, reactive airway disease, BPD flare, or pneumonia.

Table 2 Best pulmonary function over childhood and adolescence

\begin{tabular}{|c|c|c|c|}
\hline & $3-6$ years & $7-11$ years & $\begin{array}{l}12- \\
20 \text { years }\end{array}$ \\
\hline \multicolumn{4}{|c|}{ Best FEV1 (\% predicted) } \\
\hline $\mathrm{n}$ & 128 & 71 & 14 \\
\hline mean (s.d.) & $83.6(17)$ & $87.1(18)$ & $82.6(25)$ \\
\hline \multicolumn{4}{|c|}{ Best FVC (\% predicted) } \\
\hline $\mathrm{n}$ & 60 & 55 & 12 \\
\hline mean (s.d.) & $100(21)$ & $110(20)$ & $111(21)$ \\
\hline \multicolumn{4}{|c|}{ Best FEV1/FVC } \\
\hline $\mathrm{n}$ & 60 & 55 & 12 \\
\hline mean (s.d.) & $82(9.1)$ & $79(8.9)$ & $70.6(14)$ \\
\hline
\end{tabular}

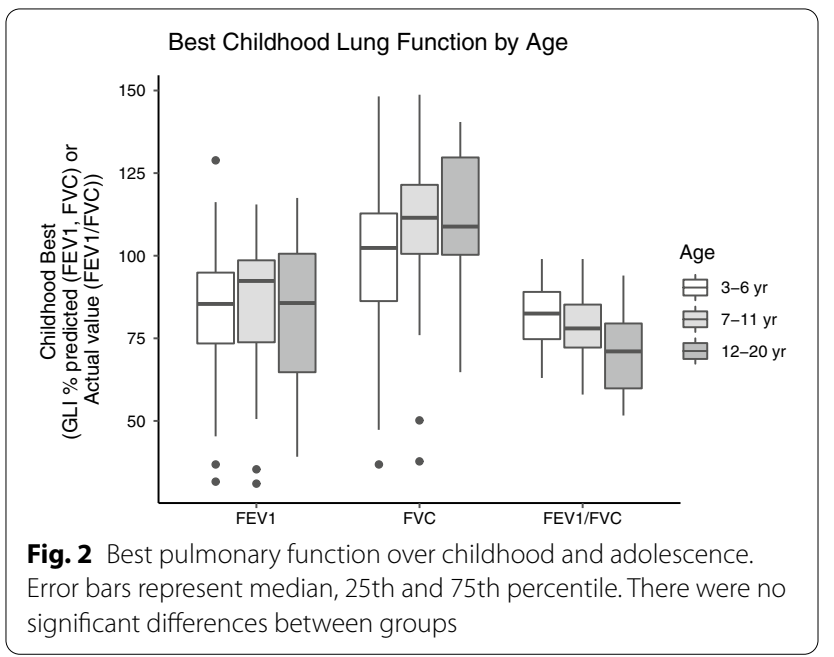

252 tests (47\%) from 98 subjects (59\%) with both acceptable $\mathrm{FEV}_{1}$ and $\mathrm{FVC}$ data (Fig. 1). Best $\mathrm{FEV}_{1}, \mathrm{FVC}$, and $\mathrm{FEV}_{1} / \mathrm{FVC}$ were reduced at ages $3-6$ years, $7-11$ years, 
and $12+$ years compared to normative values (Table 2, Fig. 2).

Post-bronchodilator testing was performed in 94 tests from 57 subjects in this sample; mean percent change in $\mathrm{FEV}_{1}$ was $12.9 \%$ (s.d. 14.3). There were 50 tests (53\%) that demonstrated a positive response to bronchodilator (as defined by change in $\mathrm{FEV}_{1} \geq 10 \%$ ); 38 subjects $(67 \%$ ) demonstrated a positive response to bronchodilator in at least one test.

\section{Pulmonary function trajectories}

Longitudinal $\mathrm{FEV}_{1}$ data were available for 81 subjects, totaling 262 year's best studies performed between 3 and 20 years of age (median 6.0 years). Serial FVC and $\mathrm{FEV}_{1} /$ FVC data were available for 47 subjects, totaling 138 studies performed between 4 and 20 years of age (median 7.0 years).

Overall, $\mathrm{FEV}_{1} \%$ predicted and $\mathrm{FVC} \%$ predicted increased over time, suggesting some degree of 'catchup' growth. However, growth in FVC \% predicted (mean $2.7 \%$, s.d. $6.1 \%$ predicted per year) outpaced growth in $\mathrm{FEV}_{1} \%$ predicted (mean $1.8 \%$, s.d. $5.8 \%$ predicted per year), resulting in an $\mathrm{FEV}_{1} / \mathrm{FVC}$ that declined over time (mean $-1.1 \%$, s.d. $3.7 \%$ predicted per year), suggesting a more obstructive pattern. Rate of rise of $\mathrm{FEV}_{1} \%$ predicted was lower for Black $(\mathrm{p}=0.03)$ and Northeast Asian $(\mathrm{p}=0.002)$ subjects, and rate of rise of $\mathrm{FEV}_{1} / \mathrm{FVC}$ was lower for Northeast Asian subjects $(\mathrm{p}=0.001)$; otherwise rate of change in pulmonary function was not different based on gender or BPD severity by univariate

Table 3 Lung function trajectories

\begin{tabular}{lccl}
\hline & $\begin{array}{l}\text { FEV1\% } \\
\text { predicted (\%)/ } \\
\text { year) }\end{array}$ & $\begin{array}{l}\text { FVC } \% \\
\text { predicted } \\
\text { (\%/year) }\end{array}$ & \multicolumn{1}{l}{$\begin{array}{l}\text { FEV1/FVC (/ } \\
\text { year) }\end{array}$} \\
\hline $\begin{array}{l}\text { Overall } \\
\text { Gender }\end{array}$ & $1.8 \pm 5.8$ & $2.7 \pm 6.1$ & $-1.1 \pm 3.7$ \\
Male (ref) & $1.8 \pm 5.9$ & $3.3 \pm 5.9$ & $-0.5 \pm 4.3$ \\
Female & $1.9 \pm 5.8$ & $2.2 \pm 6.3$ & $-1.5 \pm 3.3$ \\
Race & & & \\
Caucasian (ref) & $2.7 \pm 5.7$ & $2.5 \pm 6.4$ & $-0.46 \pm 3.3$ \\
Black & $-1.7 \pm 5.9^{*}$ & $5 \pm 6.4$ & $-2.9 \pm 5.2$ \\
Northeast Asian & $-6.9 \pm 5.3^{*}$ & $3.3 \pm N A$ & $-12 \pm N A^{*}$ \\
Other & $1.3 \pm 3.6$ & $1.8 \pm 4.4$ & $-1.2 \pm 1.4$ \\
BPD severity & & & $0.11 \pm 3.8$ \\
None/mild (ref) & $2.9 \pm 4.9$ & $3.6 \pm 6.8$ & $-1.8 \pm 3.7$ \\
Moderate/severe & $1.3 \pm 6.2$ & $2.5 \pm 6.1$ & \\
\hline
\end{tabular}

Values represent mean increase \pm s.d. $* p<0.05$. Significance determined by univariate linear regression. BPD Bronchopulmonary Dysplasia, severity defined by modified $2001 \mathrm{NHLBI}$ consensus definition. NA listed for s.d. when only single result available linear regression (Table 3). Data of children $\leq 12$ years of age at the time of testing suggest a nadir of $\mathrm{FEV}_{1} / \mathrm{FVC}$ at 8-9 years (Fig. 3a).

There was no change in pulmonary function trajectories over time by birth year (FEV1\% predicted $\mathrm{p}=0.8$, FVC $\%$ predicted $\mathrm{p}=0.5$, FEV1/FVC $\mathrm{p}=0.9$ by linear regression).

\section{Neonatal risk factors associated with abnormal lung function trajectories}

In multivariable analyses using linear regression, controlling for GA, BW, and first spirometry value, longer duration of mechanical ventilation was associated with a lower rate of rise in $\mathrm{FEV}_{1}$ \% predicted and greater decline in $\mathrm{FEV}_{1} / \mathrm{FVC}$. Postnatal steroid exposure in the NICU was associated with lower rate of rise in FVC \% predicted. Tracheostomy was associated with a greater decline in $\mathrm{FEV}_{1} / \mathrm{FVC}$; gastrostomy was associated with lower rate of rise in $\mathrm{FEV}_{1} \%$ predicted. Surgical ligation of a PDA was associated with a greater improvement in $\mathrm{FEV}_{1} / \mathrm{FVC}$ over time. Maternal asthma and atopy were associated with lower rate of rise in FEV1\% predicted; and maternal asthma was associated with a greater decline in $\mathrm{FEV}_{1} /$ FVC (Table 4).

\section{Sensitivity analyses}

Sensitivity analysis using a linear mixed effects model as opposed to the two staged linear regression revealed similar results in the effect of longer duration of mechanical ventilation associated with a lower rate of rise in $\mathrm{FEV}_{1} \%$ predicted and greater decline in $\mathrm{FEV}_{1} / \mathrm{FVC}$. The linear mixed model differed from the primary two staged model in that antenatal steroids were associated with a lower rate of rise in $\mathrm{FEV}_{1} \%$ predicted, maternal asthma was associated with a lower rate of rise of $\mathrm{FEV}_{1} / \mathrm{FVC}$, and multiple post-hospital exposures were associated with lower pulmonary function trajectories (see Additional file 2).

A separate sensitivity analysis included only spirometry from age at testing $\leq 12$ years. We found similar rate of rise in $\mathrm{FEV}_{1}$ and $\mathrm{FVC} \%$ predicted (2.1\%/year and $2.9 \% /$ year, respectively) and similar decline over time in $\mathrm{FEV}_{1} /$ FVC (-1.0\%/year). In this subset of pulmonary function studies, we found similar neonatal and maternal predictors of pulmonary function trajectories as the main analysis (see Additional file 3).

\section{Discussion}

We have demonstrated that in a cohort of U.S. born children followed longitudinally in pulmonary clinic for postprematurity respiratory disease, average lung function throughout childhood was reduced, and lung function 


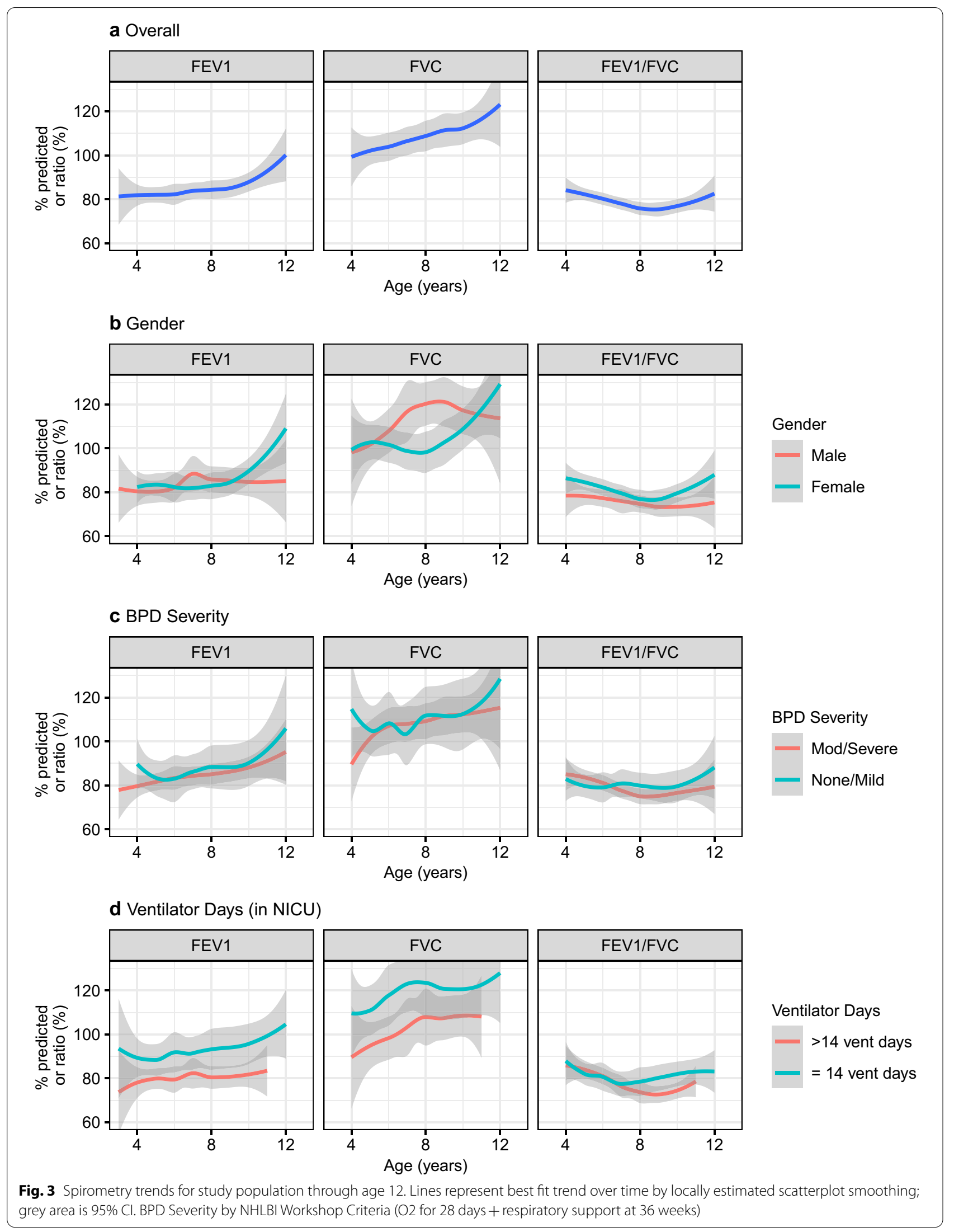


Table 4 Predictors of pulmonary function growth

\begin{tabular}{|c|c|c|c|}
\hline & FEV1 $\%$ predicted $\Delta /$ year & FVC $\%$ predicted $\Delta /$ year & FEV1/FVC $\Delta /$ year \\
\hline \multicolumn{4}{|l|}{ Neonatal } \\
\hline GA (1 week) & $-0.0038(-0.95,0.95)$ & $1(-0.28,2.4)$ & $-0.14(-0.97,0.69)$ \\
\hline BW (100 g) & $0.22(-0.43,0.87)$ & $-0.071(-0.94,0.8)$ & $0.33(-0.19,0.85)$ \\
\hline$S G A$ & $-2.4(-7.6,2.9)$ & $-1.1(-7.5,5.3)$ & $-1.2(-5.1,2.7)$ \\
\hline Multiple gestation & $-0.00061(-2.7,2.7)$ & $-2.5(-6.3,1.3)$ & $1(-1.4,3.5)$ \\
\hline Antenatal steroids (any) & $-1.6(-6,2.8)$ & $1.3(-8.3,11)$ & $-3.2(-8.6,2.2)$ \\
\hline Antenatal steroids (complete) & $1.7(-2.6,5.9)$ & $1(-5.4,7.4)$ & $0.45(-3,3.9)$ \\
\hline Surfactant & $-0.77(-9.5,7.9)$ & $4.8(-8.2,18)$ & $-5.2(-13,2.5)$ \\
\hline Ventilated days ( 1 day) & $-0.026(-0.045,-0.0074)^{*}$ & $-0.011(-0.037,0.014)$ & $-0.017(-0.03,-0.0047)^{*}$ \\
\hline CPAP days ( 1 day) & $0.011(-0.068,0.09)$ & $0.053(-0.05,0.16)$ & $-0.026(-0.09,0.038)$ \\
\hline PDA & $0.29(-3.3,3.9)$ & $-3.6(-8.8,1.7)$ & $0.6(-2.5,3.7)$ \\
\hline PDA ligation & $-0.17(-3.1,2.8)$ & $-2.1(-6.2,2.1)$ & $3.2(1.1,5.3)^{*}$ \\
\hline NEC & $2.8(-0.98,6.6)$ & $3.3(-1.5,8.1)$ & $1.2(-1.7,4.2)$ \\
\hline Severe IVH & $-2.3(-9.1,4.4)$ & $-2(-8.5,4.5)$ & $-0.66(-6.1,4.8)$ \\
\hline Postnatal steroids (in NICU) & $-2.8(-6,0.44)$ & $-3.9(-7.3,-0.38)^{*}$ & $-1.8(-5.2,1.6)$ \\
\hline Gastrostomy tube & $-3.4(-6.5,-0.3)^{*}$ & $-1.2(-4.9,2.4)$ & $0.26(-2.4,2.9)$ \\
\hline Tracheostomy & $-4.5(-9.3,0.36)$ & $-4.7(-11,1.6)$ & $-4.8(-8.3,-1.3)^{*}$ \\
\hline Discharge off breast milk & $-0.55(-2.3,1.2)$ & $1.2(-1.3,3.7)$ & $-0.19(-1.8,1.4)$ \\
\hline Any resp support at 36 weeks & $-2.1(-5.8,1.5)$ & $0.59(-4.1,5.2)$ & $-1.4(-4.4,1.5)$ \\
\hline Any resp support at discharge & $-0.028(-2.9,2.9)$ & $1.3(-2.8,5.3)$ & $-2.5(-4.9,0.021)$ \\
\hline \multicolumn{4}{|l|}{ Maternal history } \\
\hline Age & $0.16(-0.13,0.45)$ & $0.017(-0.38,0.41)$ & $-0.008(-0.23,0.21)$ \\
\hline Asthma & $-3.2(-6,-0.37)^{*}$ & $-0.75(-5,3.5)$ & $-2.1(-4.6,0.36)$ \\
\hline Eczema & $-0.13(-4.1,3.8)$ & $0.49(-4.5,5.5)$ & $1.9(-1.2,4.9)$ \\
\hline Hay fever & $-0.46(-3.9,3)$ & $-2.6(-7.3,2)$ & $-1.4(-4.2,1.3)$ \\
\hline Atopy & $-2.9(-5.7,-0.13)^{*}$ & $-2.1(-6.2,2.1)$ & $-0.33(-2.8,2.2)$ \\
\hline Secondhand smoke exposure at home & $1.3(-3.7,6.2)$ & $0.89(-5,6.8)$ & $0.57(-3,4.2)$ \\
\hline \multicolumn{4}{|l|}{ Follow-up (0-3 year) history $(n=42)$} \\
\hline Received palivizumab & $-1.7(-13,9.3)$ & $-1.3(-20,17)$ & $-4(-15,6.5)$ \\
\hline Received flu vaccination & $-2.8(-12,6.9)$ & $-0.74(-15,13)$ & $-2.8(-13,7)$ \\
\hline Any ED Visit/hospitalization & $2.1(-6.4,11)$ & $-1.5(-16,13)$ & $0.76(-8.5,10)$ \\
\hline Any hospitalization & $-11(-23,1.7)$ & $-5.3(-41,30)$ & $0.89(-12,14)$ \\
\hline Any lower respiratory tract infection & $5.2(-3.5,14)$ & $-10(-25,3.8)$ & $0.74(-14,16)$ \\
\hline
\end{tabular}

Multivariable analysis using two staged linear model, controlling for birthweight ( $B W$, gestational age (GA), and first measured spirometry value. Effect $\beta$ represents, controlling for above, change in lung function outcome per unit change in risk factor. ${ }^{*} \mathrm{p}<0.05$. SGA Small for gestational age; PDA patent ductus arteriosus; NEC necrotizing enterocolitis. When unit is listed next to risk factor, it indicates unit change for corresponding effect size on spirometry result

trajectories were abnormal with patterns becoming more obstructive over time. $\mathrm{FEV}_{1}$ and $\mathrm{FEV}_{1} / \mathrm{FVC}$ throughout childhood and adolescence were lower compared to GLI reference standards in healthy children [27]. Just over half of efforts with post-bronchodilator data showed significant improvement after bronchodilator administration; two-thirds of subjects with at least one post-bronchodilator effort demonstrated improvement an at least one effort, consistent with prior cohorts [9]. Number of ventilated days, gastrostomy tube placement, maternal atopy, and maternal asthma were associated with diminished rise in $\mathrm{FEV}_{1} \%$ predicted over time; postnatal steroid exposure was associated with diminished rise in FVC \% predicted over time; and number of ventilated days and tracheostomy were associated with a greater decrease in FVC \% predicted.

Post-neonatal exposures and events in the first years of life, including lower respiratory tract infections, rehospitalization, and RSV prophylaxis were not associated with pulmonary function trajectories later in childhood, though number of subjects with data available was smaller. Nonetheless, for RSV prophylaxis this is consistent with previous studies $[29,30]$. 
Among subjects with serial spirometry, pulmonary function trajectories became more obstructive over time. While there seemed to be 'catch-up' growth in $\mathrm{FEV}_{1} \%$ predicted and $\mathrm{FVC} \%$ predicted in this cohort, FVC growth outpaced $\mathrm{FEV}_{1}$, resulting in a declining $\mathrm{FEV}_{1} / \mathrm{FVC}$ over time. This pattern may suggest dysanaptic growth, or differential growth of the airways and lung parenchyma [31]. Both worsening obstruction and dysnapatic growth have been suggested in previous longitudinal cohorts of former preterm infants [19-24, 32-34]. Studies from the GLI have suggested that in healthy children there is a slight decrease in $\mathrm{FEV}_{1} / \mathrm{FVC}$ between ages 6 and 11 years, of about -1.5 per year overall, and less so in Caucasian children $(-0.67$ per year) and in females ( -1.2 per year) [35]. In this study, change per year in $\mathrm{FEV}_{1} / \mathrm{FVC}$ was similar $(-1.1$ per year); we also found a trend toward greater decreases in African Americans ( -2.9 per year versus -0.5 per year in Caucasians) like previous reports, but also a trend toward greater decreases in females $(-1.5$ per year versus -0.5 per year in males), which for gender is the opposite of what was shown by GLI in healthy children. Even with similar rates of change, it is notable that in this study children started with lower and more obstructed lung function, such that the dysanaptic growth that occurred resulted in worsening obstruction over time. Additionally, the data suggest an earlier nadir of 8-9 years than has been reported in healthy children (10-11 years).

To our knowledge, this is the first report of abnormal pulmonary function trajectories in a U.S. born cohort of children with post-prematurity respiratory disease in the post-surfactant era. Here we demonstrate similar findings of worsening obstruction over time. Of note, this cohort, which includes children followed in pulmonary clinic for respiratory disease related to prematurity, had higher rates of BPD, higher durations of mechanical ventilation, and greater postnatal corticosteroid use than other previously described post-surfactant era cohorts. Thus, this is more representative of a population with significant respiratory morbidity than prematurity, rather than a cohort of children born preterm overall. In the described cohort here, we demonstrate worsening airway obstruction among a population of former preterm infants with respiratory disease seeking medical followup who have the greatest need for catch up growth.

Our study also identifies risk factors in the neonatal period associated with more abnormal lung function trajectories. A recent study on an earlier cohort (1997 to 2003) in Australia also reported abnormal pulmonary function trajectories through childhood in former preterm infants, and identified earlier gestation, exposure to tobacco smoke, and greater duration of neonatal oxygen supplementation as risks for a more rapid rate of decline [24]. In our cohort, few mothers self-reported tobacco use or household exposure, suggesting underreporting. Results from these retrospective cohorts, however, do not resolve whether time on oxygen or mechanical ventilation during the neonatal period is simply an early marker of more severe pulmonary disease or is causative, through mechanisms of oxygen free radical toxicity, barotrauma, and volutrauma [36].

Our findings have implications for the trajectory of lung function in this population into adulthood. Given that children born preterm likely continue to have abnormal pulmonary growth throughout childhood raises concern that even though alveolar growth continues past the newborn period into childhood and even adolescence, these patients may not "catch up" with healthy controls with regard to pulmonary function and respiratory capacity. Due to ongoing abnormal lung growth, former preterm infants may be unable to achieve maximum normal lifetime lung function in early adulthood. Former preterm infants may also be susceptible to an earlier decline in lung function during adulthood, leading to patients with lung function that meets diagnostic criteria for Chronic Obstructive Pulmonary Disease (COPD) in early adulthood despite avoiding of toxic exposures such as cigarette smoking [24].

This is a prospective observational study that only captures subjects followed in pulmonary clinic and therefore is most applicable to the clinical population at pediatric tertiary care centers where patients with post-prematurity respiratory disease are followed and may not be generalizable to all children born preterm. Study strengths include the cohort size, the well-phenotyped population combining neonatal course details with serial spirometry data, and the recency of the cohort, enhancing external validity. Childhood environmental and infectious exposures may further affect lung function growth in this population, as has been shown in longitudinal population cohorts [37]. More extensive tracking post-neonatal symptoms exposures in early childhood will be included in future studies to assess how such exposures modify pulmonary function trajectories.

Our study population at baseline had a high degree of neonatal respiratory and non-respiratory morbidity [38]. This may have led to a selection bias, particularly among individuals with no BPD or mild BPD, to represent a population with lower pulmonary function at baseline. Notably, children unable to perform pulmonary function tests (PFTs) due to severe cognitive or neurological impairment are excluded. In addition, BPD severity was not available for $10 \%$ of subjects, based on limitations in documentation of oxygen use at 36 weeks and a physiologic test of respiratory support needs at 36 weeks was 
not routinely documented in NICU discharge summaries [39]. Given this, differences (or lack thereof) between different levels of BPD severity should be interpreted with caution. We also did not have a control population to serve as a reference standard with PFTs, and instead used internationally acceptable GLI scores to compare our cohort to a standard reference population of children. As this cohort is captured only during clinically indicated visits it is lacking ideal standardized follow-up schedule for pulmonary function. To account for this, we created linear models based on serial PFT data points to extrapolate trajectory through childhood. Although this approach has limitations, the ideal growth of pulmonary function is relatively steady during early childhood [24]. The relatively few subjects in the cohort with multiple PFTs could lead to bias toward children and those with greater illness severity. We attempted to account for those children who required multiple testing in one year by only using the year's best lung function in analyses, thus minimizing the chance for confounding the results from including sick visit PFTs. However, it is possible that the only spirometry values for a given year for an individual subject may have been in the context of a sick visit. We had limited data on maternal educational and economic status which are known to associate with pulmonary outcomes of prematurity, though may not contribute as much as maternal race, which was included [40]. We also had relatively few subjects with testing above 12 years of age, however in a sensitivity analysis only including results up until 12 years, the main outcomes did not change. Ideally, we would have had preand post-bronchodilator testing on all available subjects, but given the fact that is a clinical cohort we only have them available in subjects as clinically indicated, which limits their interpretation and likely biases the findings towards the positive association with bronchodilator response.

\section{Conclusions}

We found that former preterm infants with chronic lung disease of prematurity are at risk for reduced lung function as well as decreased trajectories of lung function growth. Neonatal risk factors including exposure to mechanical ventilation and postnatal steroids, as well as maternal atopy and asthma, were associated with ongoing poor growth in lung function throughout childhood. There is a need to better understand the lifetime trajectory of pulmonary function in former preterm infants as well as the factors associated with potential to achieve catch-up growth and to ultimately reach a normal expected maximal lung function in early adulthood. Our study suggests that despite ongoing alveolar growth past the neonatal period, lung function growth remains diminished in childhood in this cohort of former preterm infants with chronic lung disease, which may have implications for the trajectory of their lung function into adulthood putting them at risk for developing COPD.

\begin{abstract}
Abbreviations
BPD: Bronchopulmonary dysplasia; BW: Birthweight; COPD: Chronic obstructive pulmonary disease; $F E V_{1}$ : Forced expiratory volume in one second; FVC: Forced vital capacity; GA: Gestational age; GLI: Global lung function initiative; NICU: Neonatal intensive care unit; PFTs: Pulmonary function tests.
\end{abstract}

\section{Supplementary Information}

The online version contains supplementary material available at https://doi. org/10.1186/s12931-021-01720-0.

Additional file 1: Lung function scoring.

Additional file 2: Predictors of pulmonary function trajectories using alternative linear mixed effects model.

Additional file 3: Pulmonary function trajectories among studies $\leq 12$ years age.

\section{Acknowledgements}

Not applicable.

\section{Authors' contributions}

JCL had full access to all of the data in the study and takes responsibility for the integrity of the data and the accuracy of the data analysis. JCL, CPH, LMR, and LPH contributed substantially to the study design and data analysis. JCL, CAS, LMR, JMG, and LPH contributed substantially to data acquisition and interpretation. JCL drafted the manuscript, with all authors providing substantial revisions and final approval. JCL and LPH are guarantors of the submission. All authors read and approved the final manuscript.

\section{Funding}

NIH/NHLBI K23 HL136851 (LP Hayden), NIH/NIEHS R01 ES030100 (JM Gaffin), NLM T15LM007092 (Nils Gehlenborg).

\section{Availability of data and materials}

The datasets analyzed during the current study are not publicly available due to individual privacy considerations, but are available from the corresponding author on reasonable request.

\section{Declarations}

Ethics approval and consent to participate

This study was approved by the institutional review board at Boston Children's Hospital (IRB X08-07-0335). There were 38 participating subjects enrolled under a waiver of consent for retrospective review.

\section{Consent for publication}

Not applicable.

\section{Competing interests}

CP Hersh discloses relevant financial activities in the forms of grants and personal fees, outside of the submitted work (see attached ICMJE COI form). Remaining authors (JCL, CAS, JMG, LMR, LPH) have no conflicts of interests related to this study to disclose.

\section{Author details}

${ }^{1}$ Division of Newborn Medicine, Boston Children's Hospital, 300 Longwood Ave Hunnewell 4, Boston, MA 02115, USA. ²Division of Pulmonary Medicine, Boston Children's Hospital, Boston, MA, USA. ${ }^{3}$ Channing Division of Network Medicine, Brigham and Women's Hospital, Boston, MA, USA. ${ }^{4}$ Department of Pediatrics, University of Massachusetts, Worcester, MA, USA. 
Received: 21 October 2020 Accepted: 14 April 2021

Published online: 10 May 2021

\section{References}

1. Bhandari A, Panitch HB. Pulmonary outcomes in bronchopulmonary dysplasia. Semin Perinatol. 2006;30(4):219-26.

2. Broström EB, Thunqvist P, Adenfelt G, Borling E, Katz-Salamon M. Obstructive lung disease in children with mild to severe BPD. Respir Med. 2010;104(3):362-70.

3. Carraro S, Filippone M, Da Dalt L, Ferraro V, Maretti M, Bressan S, et al. Bronchopulmonary dysplasia: the earliest and perhaps the longest lasting obstructive lung disease in humans. Early Hum Dev. 2013;89(Suppl 3):S3-5.

4. Gibson A-M, Reddington C, McBride L, Callanan C, Robertson C, Doyle LW. Lung function in adult survivors of very low birth weight, with and without bronchopulmonary dysplasia. Pediatr Pulmonol. 2015;50(10):987-94.

5. Wong PM, Lees AN, Louw J, Lee FY, French N, Gain K, et al. Emphysema in young adult survivors of moderate-to-severe bronchopulmonary dysplasia. Eur Respir J. 2008;32(2):321-8.

6. Stoll BJ, Hansen NI, Bell EF, Walsh MC, Carlo WA, Shankaran S, et al. Trends in care practices, morbidity, and mortality of extremely preterm neonates, 1993-2012. JAMA. 2015;314(10):1039-51.

7. Martin JA, Osterman MJK. Describing the increase in preterm births in the United States, 2014-2016. NCHS Data Brief. 2018;312:1-8.

8. Fawke J, Lum S, Kirkby J, Hennessy E, Marlow N, Rowell V, et al. Lung function and respiratory symptoms at 11 years in children born extremely preterm: the EPICure study. Am J Respir Crit Care Med. 2010;182(2):237-45.

9. Vom Hove M, Prenzel F, Uhlig HH, Robel-Tillig E. Pulmonary outcome in former preterm, very low birth weight children with bronchopulmonary dysplasia: a case-control follow-up at school age. J Pediatr. 2014;164(1):40-45.e4.

10. Verheggen M, Wilson AC, Pillow JJ, Stick SM, Hall GL. Respiratory function and symptoms in young preterm children in the contemporary era. Pediatr Pulmonol. 2016;51(12):1347-55.

11. Vollsæter M, Clemm HH, Satrell E, Eide GE, Røksund OD, Markestad T, et al. Adult respiratory outcomes of extreme preterm birth. A regional cohort study. Ann Am Thorac Soc. 2015;12(3):313-22.

12. Landry JS, Tremblay GM, Li PZ, Wong C, Benedetti A, Taivassalo T. Lung function and bronchial hyperresponsiveness in adults born prematurely. A cohort study. Ann Am Thorac Soc. 2016;13(1):17-24.

13. Um-Bergström $P$, Hallberg J, Pourbazargan M, Berggren-Broström $E_{,}$ Ferrara G, Eriksson MJ, et al. Pulmonary outcomes in adults with a history of Bronchopulmonary Dysplasia differ from patients with asthma. Respir Res. 2019;20(1):102.

14. Jobe AJ. The new BPD: an arrest of lung development. Pediatr Res. 1999;46(6):641-3.

15. Bhandari A, McGrath-Morrow S. Long-term pulmonary outcomes of patients with bronchopulmonary dysplasia. Semin Perinatol. 2013;37(2):132-7.

16. Keller RL, Feng R, DeMauro SB, Ferkol T, Hardie W, Rogers EE, et al. Bronchopulmonary dysplasia and perinatal characteristics predict 1-year respiratory outcomes in newborns born at extremely low gestational age: a prospective cohort study. J Pediatr. 2017;187(89-97):e3.

17. Baker CD, Alvira CM. Disrupted lung development and bronchopulmonary dysplasia: opportunities for lung repair and regeneration. Curr Opin Pediatr. 2014:26(3):306-14.

18. Baraldi E, Filippone M. Chronic lung disease after premature birth. N Engl J Med. 2007;357(19):1946-55.

19. Filippone M, Bonetto G, Cherubin E, Carraro S, Baraldi E. Childhood course of lung function in survivors of bronchopulmonary dysplasia. JAMA. 2009;302(13):1418-20

20. Vollsæter M, Røksund OD, Eide GE, Markestad T, Halvorsen T. Lung function after preterm birth: development from mid-childhood to adulthood. Thorax. 2013;68(8):767-76.
21. Fortuna M, Carraro S, Temporin E, Berardi M, Zanconato S, Salvadori S, et al. Mid-childhood lung function in a cohort of children with "new bronchopulmonary dysplasia." Pediatr Pulmonol. 2016;51(10):1057-64.

22. Doyle LW, Adams A-M, Robertson C, Ranganathan S, Davis NM, Lee $\mathrm{KJ}$, et al. Increasing airway obstruction from 8 to 18 years in extremely preterm/low-birthweight survivors born in the surfactant era. Thorax. 2017;72(8):712-9.

23. Um-Bergström $P$, Hallberg J, Thunqvist $P$, Berggren-Broström $E$, Anderson $\mathrm{M}$, Adenfelt $\mathrm{G}$, et al. Lung function development after preterm birth in relation to severity of bronchopulmonary dysplasia. BMC Pulm Med. 2017;17(1):97.

24. Simpson SJ, Turkovic L, Wilson AC, Verheggen M, Logie KM, Pillow JJ, et al. Lung function trajectories throughout childhood in survivors of very preterm birth: a longitudinal cohort study. Lancet Child Adolesc Health. 2018;2(5):350-9.

25. Jobe AH, Bancalari E. Bronchopulmonary dysplasia. Am J Respir Crit Care Med. 2001;163(7):1723-9.

26. Miller MR, Hankinson J, Brusasco V, Burgos F, Casaburi R, Coates A, et al. Standardisation of spirometry. Eur Respir J. 2005;26(2):319-38.

27. Quanjer PH, Stanojevic S, Cole TJ, Baur X, Hall GL, Culver BH, et al. Multiethnic reference values for spirometry for the 3-95-yr age range: the global lung function 2012 equations. Eur Respir J. 2012;40(6):1324-43.

28. Fitzmaurice GM, Laird NM, Ware JH. Applied longitudinal analysis. 2nd ed. Hoboken: Wiley; 2011. p. 752.

29. Prais D, Kaplan E, Klinger G, Mussaffi H, Mei-Zahav M, Bar-Yishay E, et al. Short- and long-term pulmonary outcome of palivizumab in children born extremely prematurely. Chest. 2016;149(3):801-8.

30. Amitai N, Stafler P, Blau H, Kaplan E, Mussaffi H, Levine $H$, et al. Palivizumab following extremely premature birth does not affect pulmonary outcomes in adolescence. Chest. 2020;158(2):660-9.

31. Green M, Mead J, Turner JM. Variability of maximum expiratory flowvolume curves. J Appl Physiol. 1974;37(1):67-74.

32. Yammine S, Schmidt A, Sutter O, Fouzas S, Singer F, Frey U, et al. Functional evidence for continued alveolarisation in former preterms at school age? Eur Respir J. 2016;47(1):147-55.

33. Duke JW, Gladstone IM, Sheel AW, Lovering AT. Premature birth affects the degree of airway dysanapsis and mechanical ventilatory constraints. Exp Physiol. 2018;103(2):261-75.

34. Kennedy JD. Lung function outcome in children of premature birth. J Paediatr Child Health. 1999;35(6):516-21.

35. Quanjer PH, Stanojevic S, Stocks J, Hall GL, Prasad KVV, Cole TJ, et al. Changes in the $\mathrm{FEV}_{1} / \mathrm{FVC}$ ratio during childhood and adolescence: an intercontinental study. Eur Respir J. 2010;36(6):1391-9.

36. Keszler M, Sant'Anna G. Mechanical ventilation and bronchopulmonary dysplasia. Clin Perinatol. 2015;42(4):781-96.

37. Bui DS, Lodge CJ, Burgess JA, Lowe AJ, Perret J, Bui MQ, et al. Childhood predictors of lung function trajectories and future COPD risk: a prospective cohort study from the first to the sixth decade of life. Lancet Respir Med. 2018;6(7):535-44.

38. Beltempo M, Isayama T, Vento M, Lui K, Kusuda S, Lehtonen L, et al. Respiratory management of extremely preterm infants: an international survey. Neonatology. 2018;114(1):28-36.

39. Walsh MC, Wilson-Costello D, Zadell A, Newman N, Fanaroff A. Safety, reliability, and validity of a physiologic definition of bronchopulmonary dysplasia. J Perinatol. 2003;23(6):451-6.

40. Wai KC, Hibbs AM, Steurer MA, Black DM, Asselin JM, Eichenwald EC, et al. Maternal black race and persistent wheezing illness in former extremely low gestational age newborns: secondary analysis of a randomized trial. J Pediatr. 2018;198:201-208.e3.

\section{Publisher's Note}

Springer Nature remains neutral with regard to jurisdictional claims in published maps and institutional affiliations. 